\title{
UM SENSO DE COMUNIDADE
}

* Dean F. Berry

Não existe uma contradição básica entre idéias flexíveis e rígidas: construir uma comunidade e lutar contra o ceticismo são igualmente fundamentais para o sucesso.

There is no inherent contradiction between hard and soft ideas: building community and fighting cynicism are equally crucial to success.

\section{PALAVRAS-CHAVE:}

Transformação organizacional,

competitividade, senso de co-

munidade, renovação empre-

sarial, desenvolvimento organi-

zacional.

\section{KEY WOROS:}

Business transformation, competitiveness, sense of community, business reniewing, organizational development.
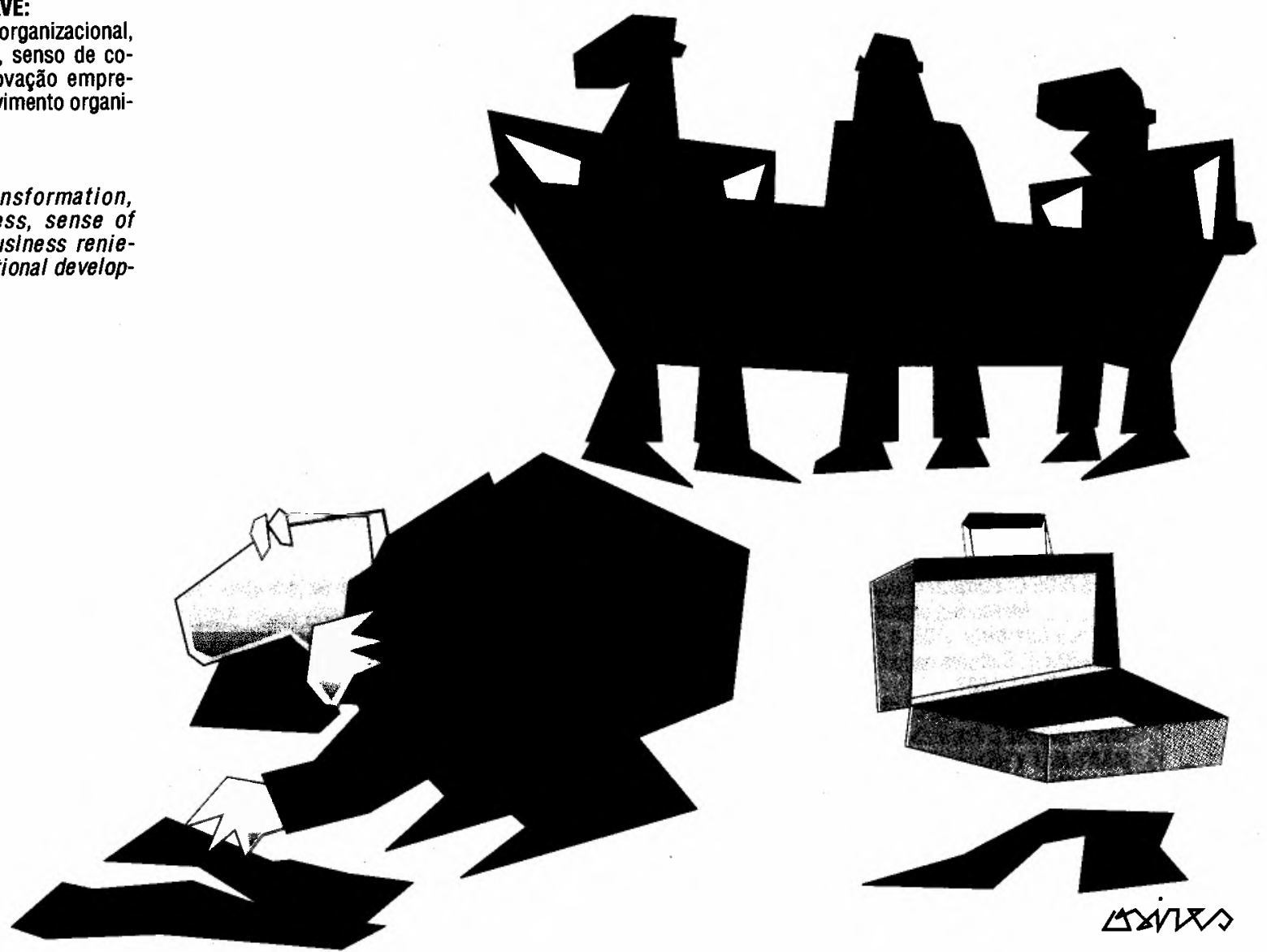

*Sócio e vice-presidente sênior da Gemini Consulting. 
A resposta que se espera de um diretor executivo à sugestão de que é preciso criar um senso de comunidade no local de trabalho geralmente é assim: "Se você está querendo dizer que criar uma 'comunidade' é o desafio decisivo para uma empresa orientada para of futuro, concordo. Mas como posso fazer isso se estou empenhado na reengenharia, em construir a empresa de amanhã?"

A grande maioria das empresas em todo o mundo está preocupada em se reestruturar e se revitalizar através da redução de custos, melhoria da qualidade e resposta ao mercado, ousadas inovações $\mathrm{e}$, de modo geral, aumento da competitividade. No entanto, embora os diretores executivos e seus experientes colegas enxerguem a necessidade de mudanças e sejam estimulados pelos desafios impostos por essas mudanças, seus programas, na maior parte das vezes, são frustrados por uma combinação de ceticismo, desconfiança, frustração e ansiedade dos próprios empregados.

O propósito deste artigo é investigar as causas deste mal que assola os empregados e sugerir algumas formas de eliminálo. O autor parte da premissa básica de que as pessoas normalmente não se comportam assim em outras esferas da sua vida; portanto, alguma coisa deve ter dado muito errado, em determinado ponto, na evolução dos métodos de gestão de empresas.

\section{A PERDA DA FÉ}

As pesquisas sociais de Yankelovich e Harris demonstram que, nos últimos trinta anos, a descrença do povo norte-americano nas suas instituições aumentou vertiginosamente.

O empresariado norte-americano só agravou essa tendência nacional de desilusão ao se mostrar incapaz de atender às expectativas de carreira criadas por suas freqüentes $-\mathrm{e}$ freqüientemente - falsas promessas.

\section{A HERANCSA DO DOWNSIZING}

Se a situação na metade da década de 80 já era ruim, o downsizing, desestratificação, metas de produtividade e os processos de reestruturação do final dos anos
80 e início dos 90 só serviram para tornála ainda pior. A seguinte mensagem, colocada no quadro de avisos de uma fábrica logo após o anúncio de demissões em massa, resultantes da fusão da empresa, traduz um pouco da angústia e do ressentimento que o processo de reestruturação normalmente provoca:

- Não sabemos dizer por quanto tempo continuaremos a operar.

- Não podemos prometer que não seremos engolidos por outra empresa.

- Não podemos prometer que haverá promoções.

- Não podemos garantir sea emprego até a aposentadoria.

- Não podemos prometer que haverá dinheiro para a aposentadoria.

- Não podemos esperar sua eterna lealdade nem temos certeza se a desejamos.

David Noer" discute a "síndrome da sobrevivência à demissão" e alerta para o fato de que a demissão é "um fato generalizado e danoso tanto para o espírito humano como para a continuidade da empresa". Seu estudo de longos anos revela que até cinco anos depois de uma demissão "persistiam os sintomas de stress, fadiga, falta de motivação, tristeza e depressão (aliados a uma carga de trabalho extra). A sensaçāo de resignação, cansaço e depressão parecia mais evidente e pronunciada... os sintomas de insegurança, ansiedade e receio também não haviam desaparecido".

O pior sintoma desta "síndrome da sobrevivência à demissão" é o que Noer chama de "co-dependência da empresa". Noer toma emprestado o termo do campo do alcoolismo, que descreve a tendência - apresentada por aqueles que estão tentando dar apoio a um alcoólatra - de investir tanta energia na missão, que negam seus próprios sentimentos e, até mesmo, alteram sua identidade a ponto de passarem a partilhar a dependência do alcoólatra.

No mundo dos negócios, as pessoas tornam-se co-dependentes da empresa quando permitem que a empresa passe a ter predominância sobre seu próprio sentimento de auto-estima, quando se sentem
1. DAVID, Noer. Healing the wounds. Jossey-Bass, 1993. 


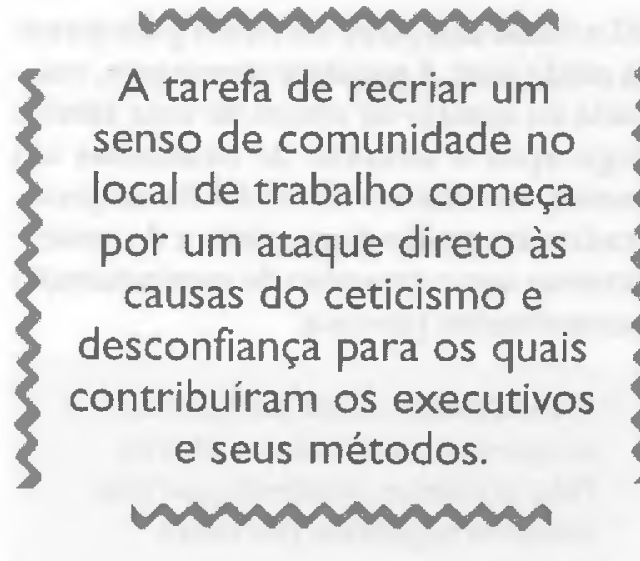

impelidas a investir toda a sua energia em tentar agradar e manipular.

Essas pessoas trabalham não pelo prazer intrínseco ou pelo desafio do próprio trabalho ou, ainda, pelo orgulho que sentem dos frutos do seu trabalho, mas, principalmente, para agradar os outros e, dessa forma, acalentar sua auto-estima. Se os empregados dessas novas organizações enxutas, totalmente renovadas pela reengenharia, são medrosos, ressentidos e

\section{O declínio da confiança}

As pesquisas sociais de Yankelovich e Harris pintam um quadro de acentuado declínio na confiança que $\cap$ povo norte-amerícano coloca em suas instituições. Yankelovich conclui que "a confiança no governo caiu drasticamente de quase $80 \%$ na década de 50 para cerca de $33 \%$ em 1976. Mais de $80 \%$ dos eleitores norte-americanos afirmam que nāo confiam mais, como antes, nas pessoas que ocupam posiçöes de lideranęa".

Em seu trabalho de 1989, The Cynical. Americans, Harris afirma que "nunca o declínio da confiança e a ascensão da desconfiança foram tão evidentes na atitude das pessoas em relação às empresas e líderes. Essa confiança despencou de aproximadamente $70 \%$ no final da década de 60 para cerca de $15 \%$ nos dias de hoje. Cada vez menos pessoas acreditam que as empresas sabem o que estão fazendo quando se trata de investir seu dinheiro ou oferecer um emprego seguro para seus empregados. Cada vez menos pessoais concordam que as empresas estão contratando, treinando e mantendo as pessoas certas para administrar as empresas". avessos a riscos, de onde virão o espírito e a criatividade que essas empresas precisam para enfrentar a batalha global da competitividade?

\section{OS PECADOS DO PASSADO}

E de onde surgiram esses empregados céticos, desiludidos, frustrados e patologicamente co-dependentes? Não nasceram assim. Portanto, a única explicação possível parece ser que este profundo descontentamento é uma conseqüência da prática gerencial.

Conhecemos suficientemente as práticas gerenciais do passado para suspeitar que as raízes da síndrome da sobrevivência e da co-dependência da empresa não estão nas demissões em si, mas no método pelo qual as forças de trabalho e organizações têm sido administradas.

J. O. Whitney ${ }^{2}$ argumenta que boa parte da desconfiança e do ceticismo atuais em relação às empresas foi institucionalizada pela má administração e que isso está complicando o problema do downsizing.

Segundo Whitney, "a segurança no futuro e a esperança de um ambiente de trabalho mais atraente, por ela criada, exigirão um alto grau de confiança - confiança em que as pessoas possam realizar seu trabalho sem se preocupar com uma supervisão exagerada, confiança em que os empregados se sintam motivados para se concentrar no cliente e não em atividades hostis e manobras burocráticas que prejudiquem a vitalidade da empresa... Uma empresa não tem o direito de esperar confiança quando apóia ou recompensa as causas da desconfiança". Whitney identifica quatro motivos principais para a desconfiança:

- desalinhamento entre avaliações e premiações;

- incompetência gerencial;

- rigidez quanto à área ou à função;

- tolerância à falta de integridade no comportamento gerencial.

A tarefa de recriar um senso de comunidade no local de trabalho começa por um ataque direto às causas do ceticismo e desconfiança para os quais contribuíram os executivos e seus métodos.

É imperativo que se faça uma limpeza 
completa e se desburocratize a prática gerencial em todas as suas facetas para que as empresas estejam efetivamente preparadas para lidar com as exigências dos negócios do século XXI, que passam por empregados preparados, senso de equipe, redes e alianças.

\section{NECESSIDADES ATUAIS}

A arena empresarial intensamente competitiva de amanhã e os novos mercados para os quais estamos reinventando nossas empresas exigem que a competitividade se torne uma qualidade presente na organização como um todo e não apenas em alguns poucos setores dela.

As qualificações e a energia de cada um não apenas devem ser aproveitadas como também cultivadas, pois o conjunto de qualificações do mundo de hoje certamente será inadequado no futuro. Todas as organizaçōes e seus membros terão que aprender a reaprender continuamente.

A conscientização cada vez maior a respeito dessas necessidades emergentes $\mathrm{e}$ urgentes se reflete na grande variedade $\mathrm{e}$ quantidade de exorlações, seminários e livros sobre empowerment (delegação de poderes), apren-

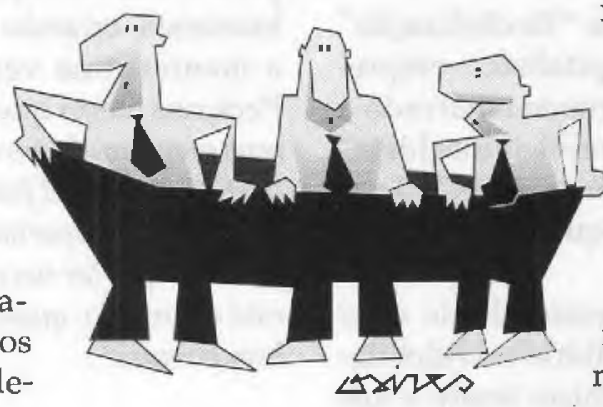

nela se concentrarem. Para alcançar esta nova forma de equilíbrio saudável nas empresa é necessário que todos os que nela trabalham, em todos os níveis, sintam a necessidade de usar novas expressões, ou seja, quase uma nova linguagem, para descrever seus sentimentos a respeito do ambiente de trabalho.

O problema é que não há normas ou receitas prontas para transformar o ambiente de trabalho em comunidade. Os exemplos de comunidades de sucesso estão se tornando cada vez mais raros fora das empresas, e os valores adotados pelas empresas na década de 80 são, hoje, extremamente inadequados como alicerces para a construção dos ambientes comunitários de trabalho exigidos na década atual.

Portanto, é preciso começar pelo começo, ou seja, pelos princípios básicos. Entretanto, a recompensa poderá ser extraordinária. O ambiente de trabalho e o próprio trabalho podem acabar sendo a pedra angular de verdadeiras comunidades vivas.

A política, a legislação, o governo e até mesmo a escola perderam o rumo, tornando-se objeto de descrença, neste momento em que a economia mundial se coloca no limiar de uma era de crescimento inédito. Taldizagem, rede de comunicações, parcerias $\mathrm{e}$ alianças estratégicas. A mensagem que está por detrás disso tudo é muito clara: a questão fundamental das organizações da próxima geração será a forma de gestão.

As vencedoras nos mercados do futuro serão as organizações que facilitarem - $\mathrm{e}$ não as que complicarem - suas atividades: as que liberarem energia humana, e

\begin{tabular}{|c|c|}
\hline $\begin{array}{l}\text { Sentimentos } \\
\text { de hoje }\end{array}$ & $\begin{array}{l}\text { Necessidades de } \\
\text { sentimentos no furturo }\end{array}$ \\
\hline Solidão & Solidariedade \\
\hline Dispersão & Integração \\
\hline Isolamento & Reciprocidade \\
\hline Abandono & União \\
\hline
\end{tabular}

RAE * v. $35 \cdot$ - n. 1 - Jan./Fev. 1995 dos no mundo dos negócios ofereçam uma oportunidade para que as empresas pela primeira vez - se transformem no carro-chefe da renovação social e na principal fonte do "senso de comunidade", cuja perda tanto sentimos. Esperamos que as empresas não deixem passar esta oportunidade.

\section{O QUE É COMUNIDADE}

Shaffer e Anundsen ${ }^{3}$ definem comunidade como "um todo (grupo ou organização) que surge quando as pessoas:

- participam de práticas em comum;

- dependem umas das outras, tomam decisões em conjunto;

- identificam-se como algo maior do que a soma de seus relacionamentos; vez a energia e os recursos a serem injeta-
3. Creating community anywhere. Shaffer and Anundsen, Tarcher/Perigree, 1993. 
- comprometem-se a longo prazo... com o bemestar do grupo".

Não só esse tipo de comunidade é necessário para a manutenção da vantagem competitiva das empresas, como os desiludidos empregados aspiram por ele no local em que passam a maior parte da vida. Margaret Mead destacou que "desde o início, o ser humano conviveu praticamente todo o tempo em grupos de 12 a 36 pessoas... Para o florescimento pleno do espírito humano, precisamos de grupos, tribos e comunidades."

Quando James Autry, ex-presidente da divisão de publicação de revistas da Meredith Corporation, afirmou que "o negócio é a nova vizinhança", estava se expressando em uma nova linguagem baseada no senso de comunidade, que também envolve a idéia de "reuniões municipais", "ginástica coletiva", "declarações de direitos e responsabilidades", "valores", "arquitetura humanizada" e "o líder como servidor".

Apesar dessa evidente "flexibilização" conceitual, o espírito capitalista e empresarial permanece firmemente amarrado à sua antiga linguagem "heróico-machista" do tipo "estou $O K$, você está OK", "que vença o mais forte" e "que se danem os outros".

A tensão entre a necessidade de criar um espírito mais comunitário e a fidelidade à nossa herança machista tende a nos levar a uma "pseudocomunidade" em que os dirigentes falam a língua comunitária, mas praticam técnicas de poder e política, oferecendo, por um lado, mais autonomia $e$ independência $e$, por outro, exercendo um controle ainda mais rígido. $O$ aspecto essencial dessas pseudocomunidades é o

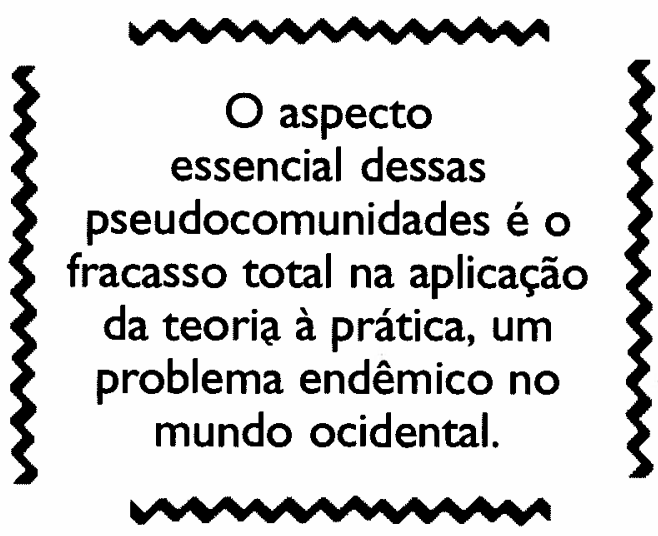

fracasso total na aplicação da teoria à prática, um problema endêmico no mundo ocidental.

\section{A ALMA HUMANA DA COMUNIDADE}

Scott Peck, em seu livro $A$ world waiting to be born, afirma que a melhor maneira de aliviar esta tensão é compreender a "falácia do individualismo arraigado". Argumenta que, embora tenhamos sido criados como indivíduos exclusivos, "somos também seres sociais que precisam desesperadamente uns dos outros para encontrar o sentido da vida. Somos chamados ao individualismo e à interdependência ao mesmo tempo".

Segundo Scott Peck, o fracasso da ética do individualismo é que "abrange apenas um lado de nosso aspecto humano". A negação do outro lado, ou seja, da necessidade de relacionamento mútuo, pode se sustentar apenas por pretensas e, portanto, pseudocomunidades. Precisamos partir para a reconciliação de nossos dois lados humanos, criando e nos comprometendo a manter uma verdadeira comunidade. Peck nos alerta que "a comunidade exige que seus membros falem o que realmente pensame sentem, com total franqueza e abertura, que se arrisquem a experimentar a intimidade, confessem o que for necessário e divulguem o que está escondido, quando tudo isto servir para o bem comum".

Dez mandamentos administrativos para combater a descrença e criar o senso de comunidade:

Oferecer às pessoas contratos realistas de trabalho (não de carreira).

Desenvolver expectativas realistas.

Estimular as pessoas a perseguirem seus interesses, e aproveitar o talento delas. Incluir nos contratos: resultados de tarefas, duração estipulada, planos de contingência, acordos de premiação e desenvolvimento, disposições de rescisão e opções de renovação.

Tornar as pessoas responsáveis pelo ambiente de trabalho.

Permitir participágâo enegociação na definição de metas pessearis e profissionais, nas atribuições do cargo e nos benefícios. Criar a figura deombudsmen e estabelecer 
"processos próprios" no local de trabalho. Formular uma Declaração de Direitos.

Concentrar o trabalho em produtos, canais de distribuição, serviços e clientes, e não em funções.

Garantir feedback rápido e responsabilidade pessoal.

Passar informaçốes, conhecimentos e poderes às pessoas dos niyeis inferiores da empresa; em geraliseo compensa.

Criar equipes para processos específicos.

Corrigir as características físicas e o simbolismo da situação de trabalho.

Oferecer status e estimular a democracia (em termos de acesso, estacionamento, refeições etc.) e respeitar mais a contribuição do que o cargo das pessoas na empresa.

As instalações físicas devem facilitar o trabalho das equipes.

Simplificar sistemas e procedimentos. Livrar-se de normas, processos, políticas e relatórios supérfluos; reduzir os procedimentos de aprovação ao mínimo necessário.

Utilizar abordagens individualizadas.

Acabar com a complexidade e a burocracia.

Agir primeiro, relatar depois; delegar poderes para estimulara iniciativa pessoal. Minimizar relacionamentos de subordinação.

Trocar as descrições de cargos pelas atribuições das equipes.

Fazer com que o sistema de informações facilite a tomada de decisões.

Aumentar o número de pessoas com acesso on-line.

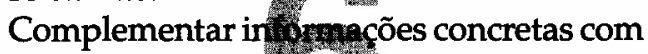
pesquisa de atith es $e$ fazer com que os dados de desempund ejam transmitidos pessoalmente.

Ouvir e recompensar sugestões.

Recompensar os administradores pela função e as equipes pelo desempenho. Colocar em prática a participação nos ganhos, pagamentos com base em qualificações, forças de trabalho assalariadas, benefícios adicionais (frituge benefits) flexíveis. Reestruturar as prewirações e sanções, de forma a se tornarem compatíveis com as novas prioridades, metas e valores. Caso contrário, é a resistência à mudança que estará sendo recompensada.

Triplicar orçamentos de treinamento: responsabilizar cada um por sua própria carreira.

Desenvolver programas sobre assuntos educativos em geral, assuntos econômicos, solução de problemas, controle de qualidade e trabalho de equipe.

Estimular a aprendizagem contínua e a troca de informações entre colegas.

Fazer com que todos se envolvam na política de pessoal.

São assuntos importantes: as políticas e procedimentos contra injustiças, horário flexível e telecom muting (uso de fax/modem), comemorações ef eventos especiais que envolvam famílias, salário-educação, licença-maternidade $/$ paternidade e creches. Permitir o máximo de variedade e escolha.

Depois de desenvolver valores e perspectivas corporativas com grupos de empregados, pedir-lhes que definam um bom trabalho em termos de filosofia e valores da empresa e coloquem por escrito uma filosofia pessoal compatível com esses valores.

Apresentar um exemplo vivo dos valores e propósitos da empresa.

Não se espantan com possíveis "baixas" (pedidos dedemiss 6 ).

Avaliar e reconpensar as melhorias conseguidas.

O passado já era, é prectso falar, agir e viver no futuro.

Dizer a verdade e nunca dizer "nunca".

A boa administração pode ser ainda melhor e, ao mesmo tempo, conseguir criar um senso de comunidade. É a única forma de derrotar o desânimo e reverter o processo de corrosão do espírito humano. As mudanças destinadas a gerar esse espírito comunitário também fazem crescer a competitividade, melhorando o nível de atendimento pela empresa das necessidades dos clientes e empregados, bem como facilitando o trabalho de equipe e a participação em redes horizontais. $\square$

\section{8}

Artigo originalmente publicado na revista Transformation, publicação externa da Gemini Consulting Inc., sob o título A sense of community. Traduzido por Attuy \& Fanucchi Consultoria Ltda. e revisto por Sonia Amaral Gama, da Gemini Consulting South America. 